\title{
Proceeding
}

Supplementary Issue: Summer Conferences of Sports Science. First International Conference in Iraq on Sport for Peace, 4 April 2019. Baghdad Science Institute, Baghdad, Iraq.

\section{The mediating role of environmental collaborations in the relationship manufacturing technologies and green innovation among firms in Thai sports industry}

\author{
CHAYANAN KERDPITAK ${ }^{1}$, WITTHAYA MEKKHAM ${ }^{1}$, CHAREEPORN SRITHONG ${ }^{2}$, KITTISAK \\ JERMSITTIPARSERT ${ }^{3,4}$ \\ ${ }^{1}$ Suan Sunandha Rajabhat University, Bangkok, Thailand \\ ${ }^{2}$ Ramkhamheang University, Bangkok, Thailand \\ ${ }^{3}$ Department for Management of Science and Technology Development, Ton Duc Thang University, Ho Chi Minh City, \\ Vietnam \\ ${ }^{4}$ Faculty of Social Sciences and Humanities, Ton Duc Thang University, Ho Chi Minh City, Vietnam
}

\begin{abstract}
The study has examined the mediating role of environmental collaborations in the relationship manufacturing technologies and green innovation among firms in Thai sports industry. The response rate of the study is 47 percent. The hypotheses are aligned with the design of research questions and by using the smart PLS 3.1.2 which is also known as the second-generation multivariate data analysis, we have analysed the reliability and validity of the instrument by the assessment of structural and measurement model. The results show the important mediating role of internal environmental collaboration between the green innovation and modern manufacturing technologies. For the examination of fundamental mechanism, the current study has addressed the need for empirical study that how the adoption of modern manufacturing technologies increases the green innovation. The results have provided the beneficial extension of modern manufacturing technologies and green innovation by ensuring that for the firms it is important to understand the fundamental relation between the adoption of modern manufacturing technologies and fostering green innovation. Firstly, the current study we have imperially examine the association between modern manufacturing technologies and green innovation at measurement level and have incorporated modern manufacturing technologies as an ancestor of green innovation. Secondly, we have also developed complete theoretical model that with the use of modern manufacturing technologies how green innovation of the firm can get benefits with important mediator that is internal environmental collaboration. Thirdly with the context of developing economy the current study will increase the literature of green innovation. Our findings will be helpful for the managers of Thai sports industry that how to deal with problems in green innovation because of implementations of modern manufacturing technologies. Keywords: Green innovation; Manufacturing; Sports; Thailand.
\end{abstract}

Cite this article as:

Kerdpitak, C., Mekkham, W., Srithong, C., \& Jermsittiparsert, K. (2019). The mediating role of environmental collaborations in the relationship manufacturing technologies and green innovation among firms in Thai sports industry. Journal of Human Sport and Exercise, 14(5proc), S2232-S2246. doi:https://doi.org/10.14198//hse.2019.14.Proc5.41

Corresponding author. Social Research Institute, Chulalongkorn University, Bangkok, Thailand.

E-mail: kittisak.jermsittiparsert@tdtu.edu.vn

Supplementary Issue: Summer Conferences of Sports Science. First International Conference in Iraq on Sport for Peace, 4 April 2019. Baghdad Science Institute, Baghdad, Iraq.

JOURNAL OF HUMAN SPORT \& EXERCISE ISSN 1988-5202

(c) Faculty of Education. University of Alicante

doi:10.14198/jhse.2019.14.Proc5.41

S2232

| 2019 | Proc5 | VOLUME 14

(C) 2019 University of Alicante 


\section{INTRODUCTION}

One of the outcomes of the increasing environmental pressure from stakeholders the green innovation (GI) has merged as a necessity as well key success factor or sustainable manufacturing performance and development. For the enhancement of $\mathrm{GI}$, the practices, growth in technologies and polices for encouraging the private and public investments many well-known economists have called. Now a days for making a lucrative green management patterns of the firms and competitive rules have been changed with the popularity of environmentalism and Strict environmental regulations (Doppelt, 2017). The green innovation creativities have been increased by the manufacturing firms, and in their fundamental business strategies they also have been integrating the $\mathrm{GI}$ (Jha, 2016). Whereas the research of $\mathrm{Gl}$ is on its initial phases yet and this phenomenon is hardly understood that how green innovation can be increased. They also questioned about general effectiveness improvement in manufacturing which have forced many firms for the investment in modern manufacturing technologies (MMT). According to the previous studies the adoption and use of the modern manufacturing technologies is linked with series of extensive benefits along with profitability, delivery, reduction in cost, increase in efficiency and manufacturing productivity, promoting the manufacturing performance and competitive advantage of the firm, improving quality and flexibility and progress in market share (Hamdoun, Jabbour, \& Othman, 2018; Haseeb, Hussain, Slusarczyk, \& Jermsittiparsert, 2019; Haseeb, Hussain, Kot, Androniceanu, \& Jermsittiparsert, 2019). In recent years may researchers have oppressed that MMT manufacturing process, planning and design may consider as key sources for innovation. By using the MMT for the confirmation of appropriate product utilization we can get different opportunities like establishment of dynamic abilities for balancing the short lifecycle of products, increase in innovation performance and competitive advantage, uncertainty between different functions sharing knowledge and different management techniques, application of pollution prevention and control technologies (Hamdoun et al., 2018). Though according to the literature, the main driver for the innovation is the adoption of MMT, the benefits of its experimental evidences on GI are limited unexpectedly. For the establishment of GI practices, the managers of the firms are concerned to know about the main drivers involved. The inadequate information regarding the possible benefits of MMT on GI can creel the development of a broadly accepted framework, which in manufacturing firms will describe and classify activities of green innovation. So, it is very important to get a general view to explore how the green innovation will be affected with the adoption of MMT (Aluko, 2017). In the current study we have tried to fill research gap with concentrating on the possible antecedents of GI specially the MMT adoption. Additionally, for understanding the MMT and its association with green innovation firstly we must examine how different types of MMT are individually associated/linked with different extents of GI. The current study has extended the previous studies by examining the association between MMT planning, design and use of process and green process innovation (GPI)and green products with the development of theoretic base by giving the empirical indication for the association between green innovation and adoption of MMT with the multidimensional perspective (Sardá \& Pogutz, 2018). Moreover, the prior studies highlighted that there cannot be a direct relationship between the green innovation and adoption of MMT.

Which calls for examining the questions that how the green innovation is influenced with the adoption of MMT. Against the earlier background we have argued that for the GI the MMT have potential value whereas with in the firm the actual affect can be achieved only when decision makers, analyst's ad experts can estimate and detect the technological knowledge. Because by nature the technical knowledge is tacit, for the achievement of green innovation and effective knowledge integration sharing of information among different departments reflect as a main competitive competence (Lin \& Chen, 2017). So, we have purposed an important organizational capability and mediator is internal environmental collaboration, over which the effective adoption of MMT can eventually lea toward green innovation. We have employed the mediation 
approach ad offering the mechanism for understanding the complete benefits of underlying the relationship between the $\mathrm{GI}$ and MMT. The current study will contribute in the literature of $\mathrm{GI}$ and MMT in many ways (Wuryaningrat, Kindengan, \& Sendouw, 2018).

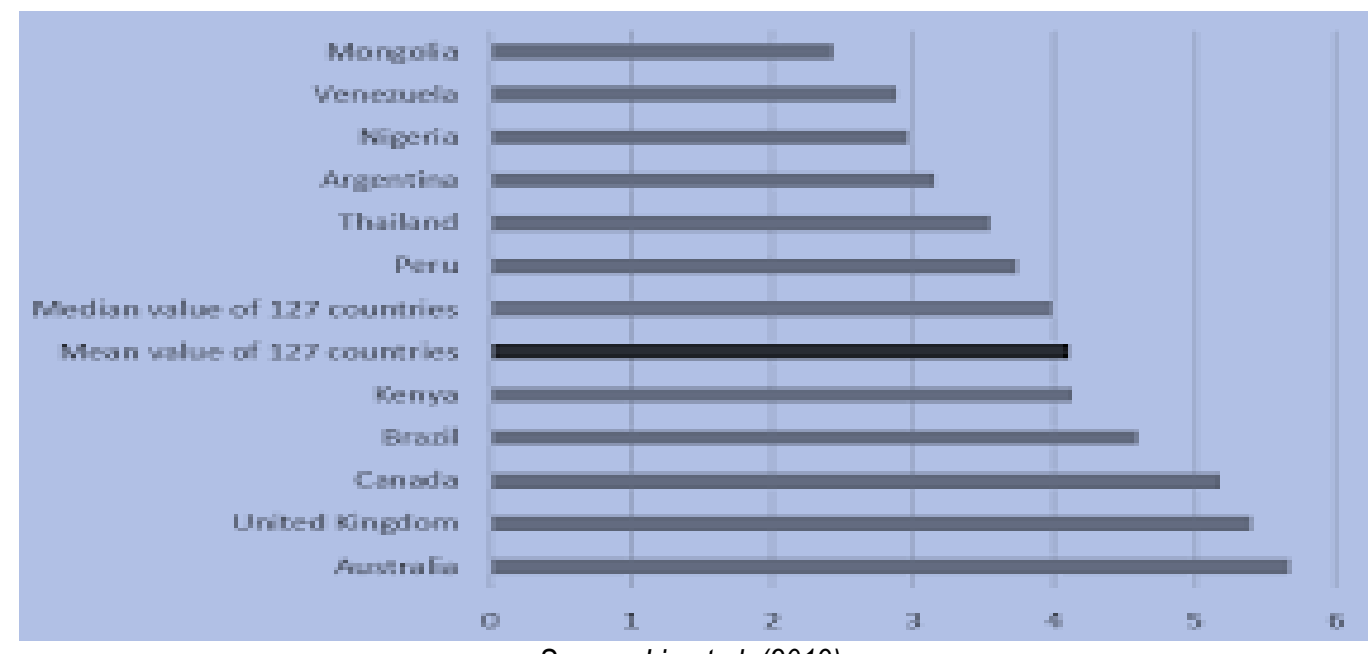

Source: Lin et al. (2019).

Figure 1. The stringency of environmental regulations and enforcement of 11 countries.

\section{LITERATURE REVIEW}

The appropriate theoretical foundations are provided by the resource-based view (RBV) of a firm and the view to understand the association between green innovation and use of MMT. As per RBV the sustainable competitive advantage of the firm is determined by the effective capabilities and unique resource and by combining the resources in the way they are non-substitutable, inimitable, rare and valuable (Epelbaum \& Martinez, 2014; Hamdoun et al., 2018). Though the important benefits of MMT are known and fundamental mechanism by which green innovation is affected is also under consideration. To fill this gap the current study has assumed that IEC mediate the effect of adopting MMT on GI. Within organization the connection of different functions like development and planning together for the environmental solutions and management, which represents the organization's fundamental competences which identify and facilitate the integration of technical knowledge to modernize the environment is known as Internal environmental collaboration (Aboelmaged, 2014). Frequently the technical knowledge is socially embedded, specialized and tacit due to which it's hard to transfer (Jermsittiparsert \& Srisawat, 2019). For know-how in different departments the IEC have provided the interactive and direct access. Furthermore, commitment and trust which is derived from the IEC can increase the motivation level of employees for sharing their exclusive technological knowledge, through which knowledge transfer efficacy integration to Green innovation increase. Therefore, the IEC may act as an important capability of organization which can enhance the probability of possible green innovation offered by MMT. So, our focus will be on IEC as mediator between the green innovation and adoption of MMT (Kyriakopoulos \& Arabatzis, 2016; Sardá \& Pogutz, 2018). The range of potential development paths can be expanded significantly with huge investment in MMT. According to the literature the implementation of MMT in manufacturing firms provides many benefits. For the improved quality the literature has supported the following practices that are manufacturing performance, competitive advantages of firm, flexibility, efficiency and manufacturing productivity of the firm (Hamdoun et al., 2018). Furthermore, implementation of MMT can also be effective for the firms who are engaged in activities of high value addition like innovation. From the manual operation to mechanized technology the effected changes are marked by MMT (Bharadwaj, 
2018). Within the manufacturing firm from the preliminary adoption of MMT over the programming and system design for implementing the continuous improvements, on the process innovation and green product the use of MMT has great effect on both. The adoption of MMT nurture the green product innovation in two different ways firstly by using the planning, process and design MMT helped in creation of knowledge-based sources for modern competences of manufacturing which also contribute in development of GPI. The implementation of long-term effectiveness of AMT is mainly depends on rich knowledge base of the firm. The conditions of adopting MMT are usually involved combining the new technical knowledge and transformation of general knowledge to economically valuable knowledge generating, assimilation and acquiring (Raman, 2016). Generally, the technical knowledge is intangible like understanding that or know about how to adopt the technology which is developed by others. $\mathrm{Gl}$ is depending on the availability of knowledge, so foe the guaranteed success of GI we must recognize the knowledge base created by the MMT. By organizing the base of knowledge MMT provides the different platforms, processes and tools to confirm the accessibility and availability of knowledge. Distribution and development of technical knowledge increase the quickness of sustainable production. For example, the development in product knowledge and quickness of technical knowledge provides the facility of recovering the end life of firm's product and its reprocessing (Cui \& Wu, 2016). Additionally, over the provision of tools and technical platforms for collaborative learning and sharing the knowledge, MMT can facilitate the teamwork as mechanism of adopting the innovation. In short, the implementation of MMT have high potential to enable the teamwork by improving the assistance between the partners of supply chain ad internal departments. The activities of teamwork regarding knowledge sharing and interactions related to environment like the workshops and training related to $\mathrm{Gl}$, product design and contribution in development of technical environment consequently increase the chances of green product development (Charter \& Tischner, 2017). In a complex manufacturing system, the use of MMT will help in increasing the competence of industrial system, thus it can be an important source for the product innovation which influences the environmental advantages related to the creativity and design. Installation of modern technology for the green production and high investments for the green equipment's may increase the productivity of the resources in that way for reduction in environmental cost have positive impact of GPI (Ma, Hou, \& Xin, 2017). Additionally, with MMT companies can stimulate the actions of proactive environment like redesigning, alterations with cost saving possibility the creation of new products therefor facilitating the GPI. On the green product innovation, the adoption of MMT have positive effect by using the planning, process and design. GPI frequently integrates the modifications redesign and the new product creation, in production processes which are mainly associated with technological changes (Dangelico, Pujari, \& Pontrandolfo, 2017). MMT is that type of technology which supports organizational process and production and has become an actual way of disabling the hurdles and making that type of manufacturing process which can reduce the harmful impacts on environment. In reply to change in environmental regulations and technology, MMT can mainly increase the green product innovation over developing the competences or widely changing the process solutions in organization. MMT design is not only for the ideas and concepts, innovative products collaboration and effective communication but it has also combined the functionality (Lii \& Kuo, 2016), enable the calculation, operation of dynamic product information for providing the improved quality of product features for the customers who are conscious about the environment. Whereas the MMT planning allows firms for managing their material flows and optimize the production schedules for improving their efficiency and proper utilization of manufacturing resources (Jha, 2016). The real representation of unproductive resources is pollution. Through the MMT planning the resource productivity of the manufacturing firms and green product innovation can be increased, and environmental cost can be decreased (Sirkeck \& Gupta, 2017). MMT being an important factor can increase the GPI. So, we have purposed the following hypothesis based on the above discussion.

H1: The use of process AMT has significant impact on the green product innovation.

H2: The use of design AMT has significant impact on the green product innovation. 
H3: The use of planning AMT has significant impact on the green product innovation.

Moreover, to GPI, on green process innovation the adoption of MMT too have a positive effect. By increasing the processing and information sharing capabilities of the firm, MMT mainly increases the green process innovation (Merino, Ludueña, \& Alvarez, 2018). For the successful implementation of MMT sharing ad processing of effective information is very important. By using the MMT employees efficiently interact and within the organization it also allows the direct access to database of product and real time information sharing in control means. Across the practical boundaries it has leading potential to interact and communicate deeply. Which as a result improves the cross-functional teamwork/collaboration? Innovation capabilities can be improved in early phases of developing new product with the collaboration of different departments (Parida, Sjödin, \& Lenka, 2015). In this way innovative performance can also be foster. Similarly, MMT adoption can be helpful for the green innovation among the various functions sharing the information regarding the quality ad eco design. On the other side the information processing abilities of MMT, allow the employees on the factory floor apply for the creative solutions of problems, as a result improve the process ad product. According to Kong, Feng, and Ye (2016) Whereas the know-how and processing of green information guide about the activities of green innovation. So, for the manufacturing firms it is very important for being capable of GPI they should employ the MMT. Furthermore, Green process innovation can be increased with the adoption of planning, design and process of MMT. Because of the limits in flow of information mostly manufacturing process apparently are barriers (Trianni, Cagno, \& Farné, 2016). The focus of process MMT is on manufacturing characteristics, delivery and production is the requirement for creating the information linked with operational process. The application of MMT process helps in increasing the integration of information and operational process. For instance, technologies such as environmental control system is probable for improving the information based for GPI. For the improvement of green process innovation using the MMT design is also effective (Dahab, Maag, \& Bagnato, 2016). The designed technologies like CAE and CA are linked with designers with manufacturers, customers and suppliers by using language and interface of common software, which provides the customers' requirements and feed the data design directly in the production system. The environmental practices of companies can be influenced with the Involvement of suppliers and expectations of customers. So, the important driver of green process engineering is the use of common language, meanwhile for the pursual of development opportunities of green innovation it promotes the design integration and manufacturing activities (Zhang \& Zhu, 2019). Lastly the MMT planning recommends its benefits in GPI. by carrying the computational and automation power collected in the synchronized decision-making, for the utilization of resources at optimal level the MMT planning like MRP II and ERP are helpful in providing the efficient plans for the environmental process for meeting the environmental regulations. Therefore, we have purposed that green process innovation can be improved by using the MMT as exemplified in the hypothesis below (Invernizzi, Locatelli, \& Brookes, 2018).

H4: The use of process AMT has significant impact on the green process innovation.

H5: The use of design AMT has significant impact on the green process innovation.

H6: The use of planning AMT has significant impact on the green process innovation.

However, to stimulate the green innovation of the firm probably uses of planning, design and process MMT, know less regarding the fundamental mechanism linked with the green innovation and adoption of MMT. From the RBV logic the internal environmental integration may identified as exceptional capability (Bromiley \& Rau, 2016). Which may likely to translate MMT into enhanced green innovation performance (GIP). So, we have purposed that internal environmental integration mediate the impact of adopting MMT on process innovation and green product. An organization may adopt the different modern technologies whereas the green innovation might not be able to get benefits from such diversification if its internal departments are reluctant for making the proactive environmental integration. According to the many researchers, Schubert 
and Tavassoli (2019) and Aluko (2017) the successful adoption of MMT required proper coordination and communication among the specialists of process and product. Without the application of internal collaboration of value adding functions it is improbable the successful investment in MMT. So, minimizing the conflict and for the successful dealing with strategic ad technical interdependencies characteristics in the adoption of modern technology, the cooperation should be carried out by the representatives from different departments. With the linkage of different functional departments, mutual databases and information system. The internal environmental integration consists on the exchange of policies on sharing the technical information and for the establishment of mutual goals, the functional addition which enables the collaboration between decision makers, analysts and the experts. For the development of new skills, reduction in the potential confrontation, fostering trust, ad specially the actual coordination is essential for the green innovation. Additionally, for achieving the products, the focus of environmental collaboration is on the comprehensive means of environmental operations. The requirement of active orientation of environmental management is that firms should stop the deprivation of environment with innovative point of view for the development of products that are environment friendly ad these practices are positively related with $\mathrm{GI}$ (Charter \& Tischner, 2017). For improving the environment, the mutual willingness is required to learn about the functions of each other's, set the mutual goals and plan accordingly. With the utilization of MMT the collaboration of internal environment lead towards the systematic solution of advance product and process for environment (Bajwa, 2018). For the sharing of inter firm knowledge the internal environmental partnership is the key channel. Within the organization by dispersing, communicating, integrating ad with the learning of modern technology the internal environmental integration facilitates the activities of synchronization of product, technical knowledge sharing and process technology progress (Enkel, Groemminger, \& Heil, 2018). Furthermore, over the Informal and formal mechanism the internal environmental integration includes the combine planning meetings, related to environment and activities of knowledge sharing like seminars, workshops ad meetings related to management, increase the ability of a firm to integrate environmental ad technical knowledge. In this manner technological knowledge acquisition is in complementary support of organizational $\mathrm{GI}$. On the other side the important learning capability is presented by the integration of internal environment. The learning capacity is required by the potential of MMT. Within the firms the by interaction between the different departments IEC facilitate the updates of tacit knowledge specifically related to technical interdependency among the specifications of manufacturing process and product specifications for stimulating the creation of new alternatives (Huenteler, Ossenbrink, \& Schmidt, 2016). So, the IEC indicates the important mediator by which MMT contribute towards green innovation. Thirdly resource productivity and technologies can be increased by the organizations with the help of IEC for the fostering of environmental innovations. The environmental integration requires the investment of particular resources in the collaborative activities by the organization for addressing the issues related to environment. For capturing the value addition, internal environmental collaboration is useful, which arises from a cooperative interaction of various functions for promoting the innovation that decreases environmental effect. Additionally, with the cooperation of cross function the IEC also accelerates the application of process- or product-based changes and consequently lead the environmental adjustments in the process or product of focal plants. In short, the IEC might miss the relation between green innovation and adoption of MMT (Sardá \& Pogutz, 2018). Therefore, we have suggested that planning, design and process MMT have prospective advantages on the green innovation of a firm and primarily through the internal environmental collaboration these constructive effects can be achieved.

H7: IECOL mediates the relationship between product process AMT and green product innovation. H8: IECOL mediates the relationship between product design AMT and green product innovation. H9: IECOL mediates the relationship between planning design AMT and green product innovation. H10: IECOL mediates the relationship between product process AMT and green process innovation. H11: IECOL mediates the relationship between product design AMT and green process innovation. 
H12: IECOL mediates the relationship between planning design AMT and green process innovation.

\section{METHODOLOGY}

We had circulated the questionnaire to total 570 SME's of sports sector of Thailand, as per the previous studies the response rate was $0.20 \%$ for the various sectors of Thai SME's, so the estimated response rate was 47 percent. We had planned the questionnaire for the decision makers of the firm. So, for all the responses of respondent, we have considered the decisions of firms. For the analysis of current study, we have used the most important statistical tool that is PLS-SEM. According to the Hair, Hult, Ringle, and Sarstedt (2016) and Hair, Sarstedt, Hopkins, and Kuppelwieser (2014) the minimum requirement of sample size is 10 times to the highest number of variables for the analysis. The recommended sample size for the multivariate analysis for every variable is 15 subjects as per the study of Hair, Hult, Ringle, and Thiele (2017), therefor the suitable size for this study is 325 respondents, that will utilize the 21 independent and dependent variables. Although because of the two reasons we may accept the huge sample size there is possibility of biasness effect on small sample size. By depending on the small sample size there is possibility of sampling error because of that the affected population may not reflected. We have employed the inferential and descriptive statistic for the analysis of collected data of the current study. For screening the data, for the analysis of collected data, profile of respondent we have used SPSS 22. We have also measured the satisfaction level of lecturer's job. We have categorized the seven-point Likert scale into five as 1.00-2.20 as very low; 2.21-3.40 as low, 3.41-4.60 as moderate, whereas 4.61-5.80 as high and 5.81-7.00 as very high (Subramanian, Gunasekaran, \& Abdulrahman, 2019). The hypotheses are aligned with the design of research questions and by using the smart PLS 3.1.2 which is also known as the second-generation multivariate data analysis, we have analysed the reliability and validity of the instrument by the assessment of structural and measurement model. The PLS-3 software allows users to detect any possible missing data; the missing value settings in the PLS-3 was used and it was discovered that there is not any item that was not responded to by the respondents.

\section{MEASURE}

In the current study we have used the Green innovation and internal environmental collaboration as the measures of MMT, which were adopted by many previous studies. By using a Likert scale of seven points we have measured the indicators, high values show the improved performance or high level of collaboration and technology application in green innovation of firm. According to the literature the MMT has abstracted as multidimensional construct (Sardá \& Pogutz, 2018). By considering the previous studies we have measure the MMT in three different ways: planning MMT, design MMT, and process MMT. These dimensions of MMT are controlled as three, four and five scales, and we have measured these dimensions by adopting the measurement scale from the previous studies. The environmental control system and CAM technologies are included in process MMT. Which enables the flexible and efficient manufacturing process. The technologies which assist in designing the process and products like PDM and CAM are incorporated in design MMT. The MMT planning is focused on the important resources of the firm and encompasses technologies like MRP II and ERP etc. by asking the respondents to specify the extent at which the practice or technology have utilized in their plan for managing the environment we have evaluated the constructs related to the average of industry. 


\section{DATA ANALYSIS}

Smart PLS-3 is a variation of multiple regression and correlation analysis. It is used to estimate path and loading coefficient (Ahmadian \& Abdolmaleki, 2018). PLS-3 is use for the estimation of average variance extraction. It is use for bootstrapping the data set. It is also use for the analysis of the data when the model is complex and whereas in this study there are four constructs which are in second order form Hair et al. (2017). It is also essential because of the items in the study are formative and 75 reflective in nature which other software analysis may not appropriately handled (Hair et al., 2016). Furthermore, PLS-3 is suitable for this study as it takes good account of measurement error. Using the PLS-3 approach to source information regarding the relationship between the variables we had carried out the analysis by forming a model which is refers as the structural model (Ahmadian \& Abdolmaleki, 2018). We have used the Smart PLS for the assessment of measurement of the variables in this study and for the confirmation of relationship among variables as well as the prediction. PLS was also used to show importance-performance matrix analysis in the study.

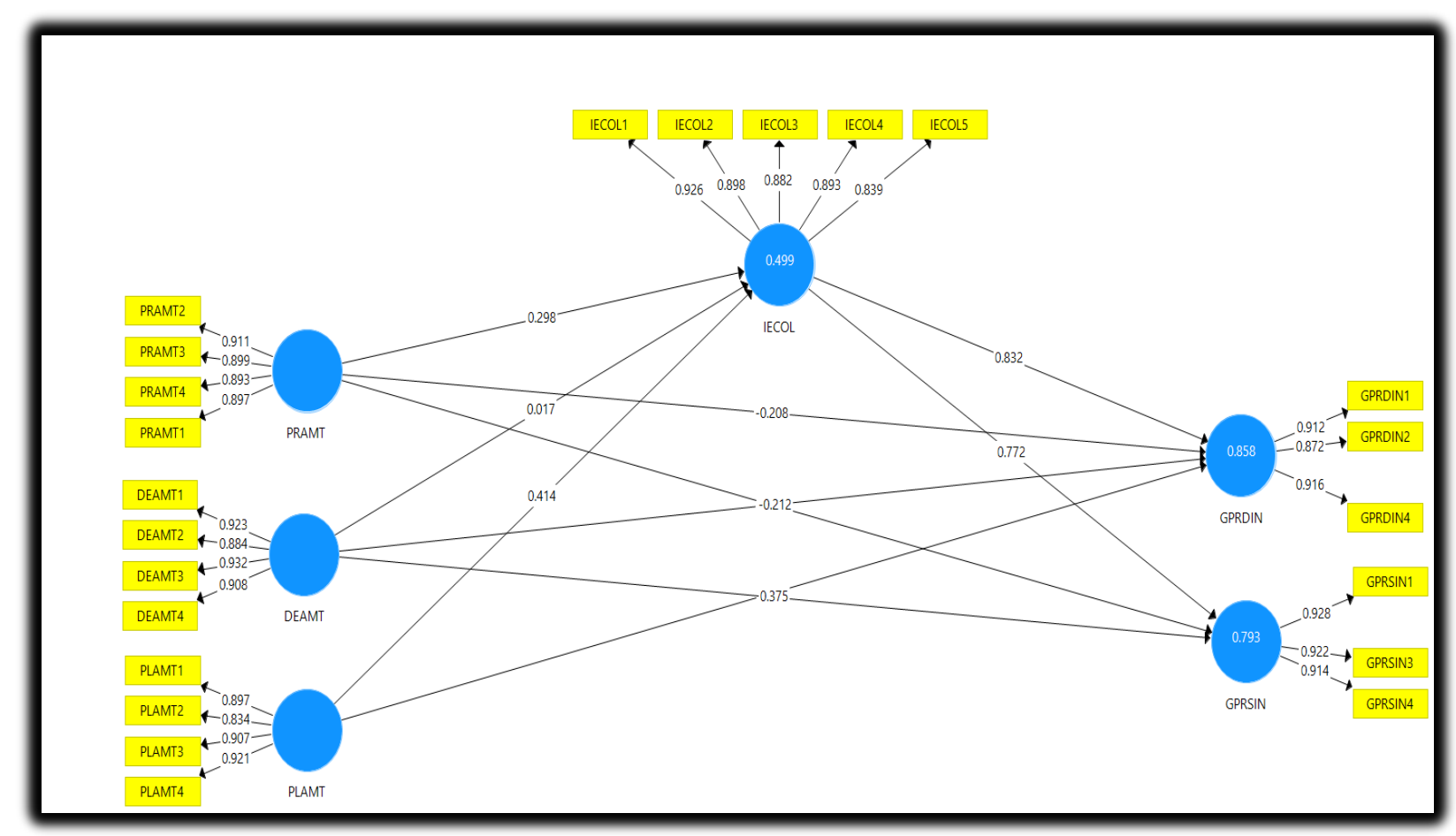

Figure 2. Measurement Model.

Measurement model the study of Hair et al. (2014) indicates the association among the latent or unobserved and observed variables measured variables (items/indicators/ scales for each construct). In evaluating the measurement model, we have carried out the CFA to measure the construct validity (discriminate validity and convergent validity) and reliability of the items. The average variance extracted (AVE) as well as the composite reliability (CR) for the variables in the study was calculated. According to Henseler, Ringle, and Sarstedt (2015), the CR must be $\geq 0.7, A V E \geq 0.5$ while Lonial and Carter (2015) recommends a value of 0.7 for the Cronbach alpha. The convergent validity is ascertained when the outer model loadings are greater than 1.96 at 0.05 level of significance. Once the measurement model is validated and found reliable, the structural model was also assessed. 
Table 1. Outer Loading.

\begin{tabular}{|l|l|l|l|l|l|l|}
\hline & DEAMT & GPRDIN & GPRSIN & IECOL & PLAMT & PRAMT \\
\hline DEAMT1 & 0.923 & & & & & \\
\hline DEAMT2 & 0.884 & & & & & \\
\hline DEAMT3 & 0.932 & & & & & \\
\hline DEAMT4 & 0.908 & & & & & \\
\hline GPRDIN1 & & 0.912 & & & & \\
\hline GPRDIN2 & & 0.872 & & & & \\
\hline GPRDIN4 & & 0.916 & & & & \\
\hline GPRSIN1 & & & 0.928 & & & \\
\hline GPRSIN3 & & & 0.922 & & & \\
\hline GPRSIN4 & & & 0.914 & & & \\
\hline IECOL1 & & & & 0.926 & & \\
\hline IECOL2 & & & & 0.898 & & \\
\hline IECOL3 & & & & 0.882 & & \\
\hline IECOL4 & & & & 0.893 & & \\
\hline IECOL5 & & & & 0.839 & & \\
\hline PLAMT1 & & & & & 0.897 & \\
\hline PLAMT2 & & & & & 0.834 & \\
\hline PLAMT3 & & & & & 0.907 & \\
\hline PLAMT4 & & & & & 0.921 & \\
\hline PRAMT2 & & & & & & 0.911 \\
\hline PRAMT3 & & & & & & 0.899 \\
\hline PRAMT4 & & & & & & \\
\hline PRAMT1 & & & & & & 0.893 \\
\hline
\end{tabular}

Table 2. Reliability.

\begin{tabular}{|l|l|l|l|l|}
\hline & Cronbach's Alpha & rho_A & CR & (AVE) \\
\hline DEAMT & 0.933 & 0.936 & 0.952 & 0.832 \\
\hline GPRDIN & 0.883 & 0.884 & 0.927 & 0.810 \\
\hline GPRSIN & 0.911 & 0.914 & 0.944 & 0.849 \\
\hline IECOL & 0.933 & 0.934 & 0.949 & 0.789 \\
\hline PLAMT & 0.913 & 0.917 & 0.939 & 0.793 \\
\hline PRAMT & 0.922 & 0.922 & 0.945 & 0.810 \\
\hline
\end{tabular}

Table 4. Validity.

\begin{tabular}{|l|l|l|l|l|l|l|}
\hline & DEAMT & GPRDIN & GPRSIN & IECOL & PLAMT & PRAMT \\
\hline DEAMT & 0.902 & & & & & \\
\hline GPRDIN & 0.848 & 0.900 & & & & \\
\hline GPRSIN & 0.786 & 0.877 & 0.901 & & & \\
\hline IECOL & 0.743 & 0.815 & 0.869 & 0.888 & & \\
\hline PLAMT & 0.786 & 0.794 & 0.693 & 0.692 & 0.890 & \\
\hline PRAMT & 0.671 & 0.745 & 0.638 & 0.678 & 0.884 & 0.900 \\
\hline
\end{tabular}


Multicollinearity test was carried out by examining the VIF value, tolerance value as well as the condition index for the independent variables. Acceptance indicate the amount of change of independent variable not described by the additional IV in a structural model, while Variance Inflating Factor (VIF) is that level at which standard error has been inflated due to the presence of collinearity. A condition index $(\mathrm{Cl})$ on the other hand in formative measurement models evaluate the existence of important level of collinearity (Amaro \& Duarte, 2016). An acceptance of 0.20 or smaller: VIF of 5.0 or higher and condition index of 30 or higher suggest a multicollinearity problem. Results revealed, the tolerance values go above 0.20 and all the VIF values are not more than 5 , the tolerance values go above 0.20 and; the condition index are less than 30 . Therefore, in the current study the multicollinearity is not a problem.

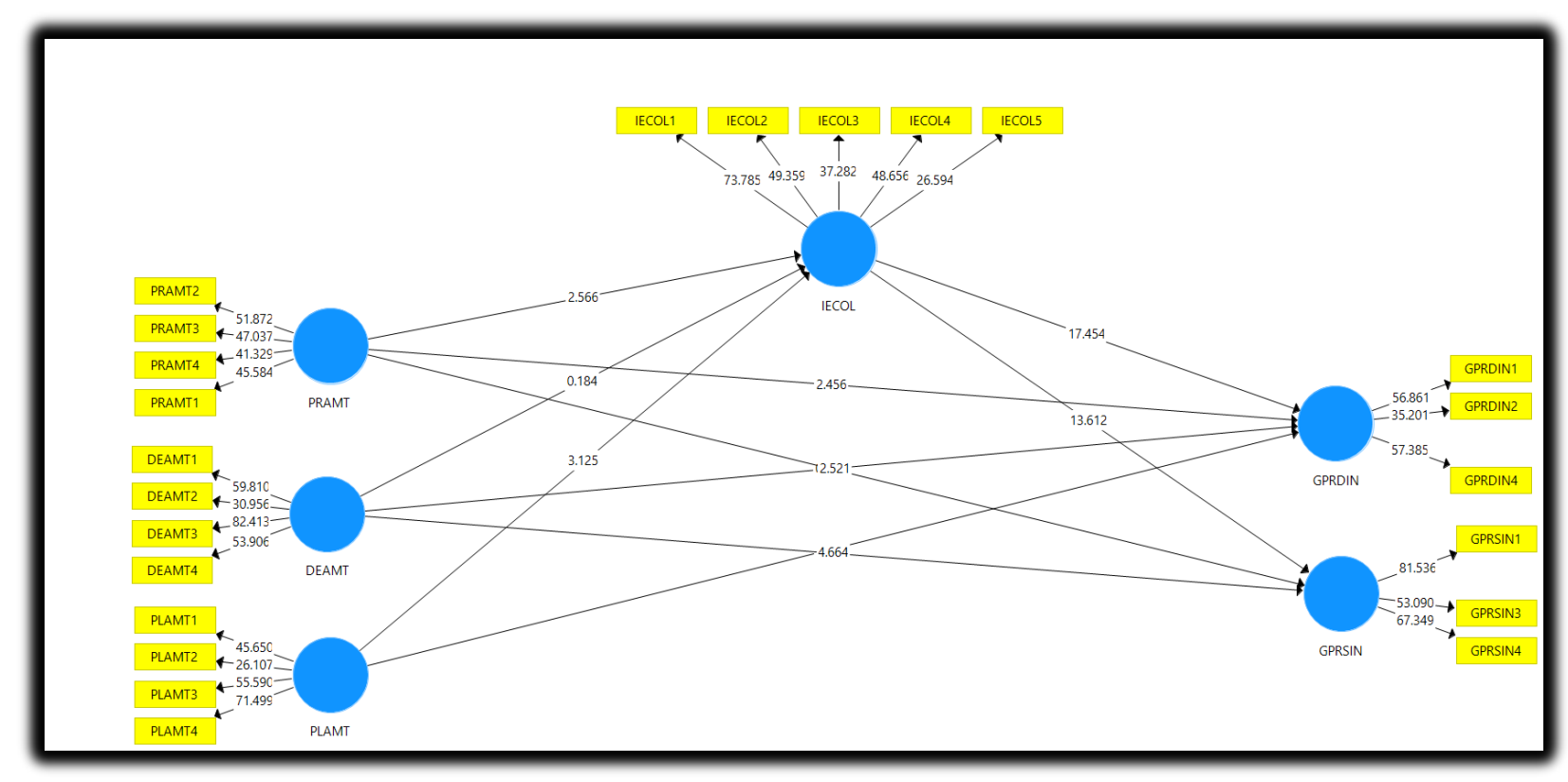

Figure 3. Structural Model.

The SM according to Hair et al. (2014) deals with dependent relationships connecting the constructs in the hypothetical model. It is a useful representation of interrelationships among constructs i.e. it explains the relationship between latent variables. The relationship among the variables in the formulated hypotheses in this study as indicated in the model was tested through the structural model. The structural model comprised of the exogenous variables.

Table 4. Direct Relationship.

\begin{tabular}{|l|l|l|l|l|l|}
\hline & $(\mathbf{O})$ & $(\mathbf{M})$ & $($ STDEV $)$ & $(\mid \mathbf{O} / \mathbf{S T D E V})$ & P Values \\
\hline DEAMT -> GPRDIN & 0.040 & 0.048 & 0.080 & 0.503 & $\mathbf{0 . 3 0 8}$ \\
\hline DEAMT -> GPRSIN & 0.375 & 0.380 & 0.080 & 4.664 & $\mathbf{0 . 0 0 0}$ \\
\hline IECOL -> GPRDIN & 0.832 & 0.825 & 0.048 & 17.454 & $\mathbf{0 . 0 0 0}$ \\
\hline IECOL -> GPRSIN & 0.772 & 0.764 & 0.057 & 13.612 & $\mathbf{0 . 0 0 0}$ \\
\hline PLAMT -> GPRDIN & 0.287 & 0.287 & 0.095 & 3.026 & $\mathbf{0 . 0 0 1}$ \\
\hline PRAMT -> GPRDIN & -0.208 & -0.210 & 0.085 & 2.456 & $\mathbf{0 . 0 0 7}$ \\
\hline PRAMT -> GPRSIN & -0.212 & -0.208 & 0.084 & 2.521 & $\mathbf{0 . 0 0 6}$ \\
\hline
\end{tabular}


Table 5. Mediation.

\begin{tabular}{|c|c|c|c|c|c|}
\hline & (0) & (M) & (STDEV) & |O/STDEV|) & P Values \\
\hline DEAMT -> IECOL -> GPRDIN & 0.014 & 0.023 & 0.078 & 0.185 & 0.426 \\
\hline PLAMT -> IECOL -> GPRDIN & 0.344 & 0.335 & 0.109 & 3.146 & 0.001 \\
\hline PRAMT -> IECOL $>>$ GPRDIN & 0.248 & 0.243 & 0.095 & 2.606 & 0.005 \\
\hline DEAMT -> IECOL -> GPRSIN & 0.013 & 0.021 & 0.072 & 0.186 & 0.426 \\
\hline PLAMT $->$ IECOL $>>$ GPRSIN & 0.319 & 0.311 & 0.107 & 2.978 & 0.001 \\
\hline PRAMT -> IECOL $>>$ GPRSIN & 0.230 & 0.224 & 0.086 & 2.681 & 0.004 \\
\hline
\end{tabular}

For the significance and relevance of the SM relationship, the predictive relevance (Q2), effect sizes, and level of R2 all these collinearity issues were assessed by the structural model. Bootstrapping was used to generate the t-statistics and the standard errors as for the estimation of PLS accuracy it shows a nonparametric approach. However, which allowed the researcher for the assessment of path coefficient statistical significance. The coefficient of determination (R2) demonstrated the ability of all the exogenous or independent variables in predicting the endogenous or dependent variable. According to Hair et al. (2014), $\mathrm{R} 2$ is a measure of the goodness of fit against the empirically manifest items obtained with values ranging from 0 to 1.

Table 6. R-square.

\begin{tabular}{|l|l|}
\hline & R Square \\
\hline GPRDIN & 0.858 \\
\hline GPRSIN & 0.793 \\
\hline IECOL & 0.499 \\
\hline
\end{tabular}

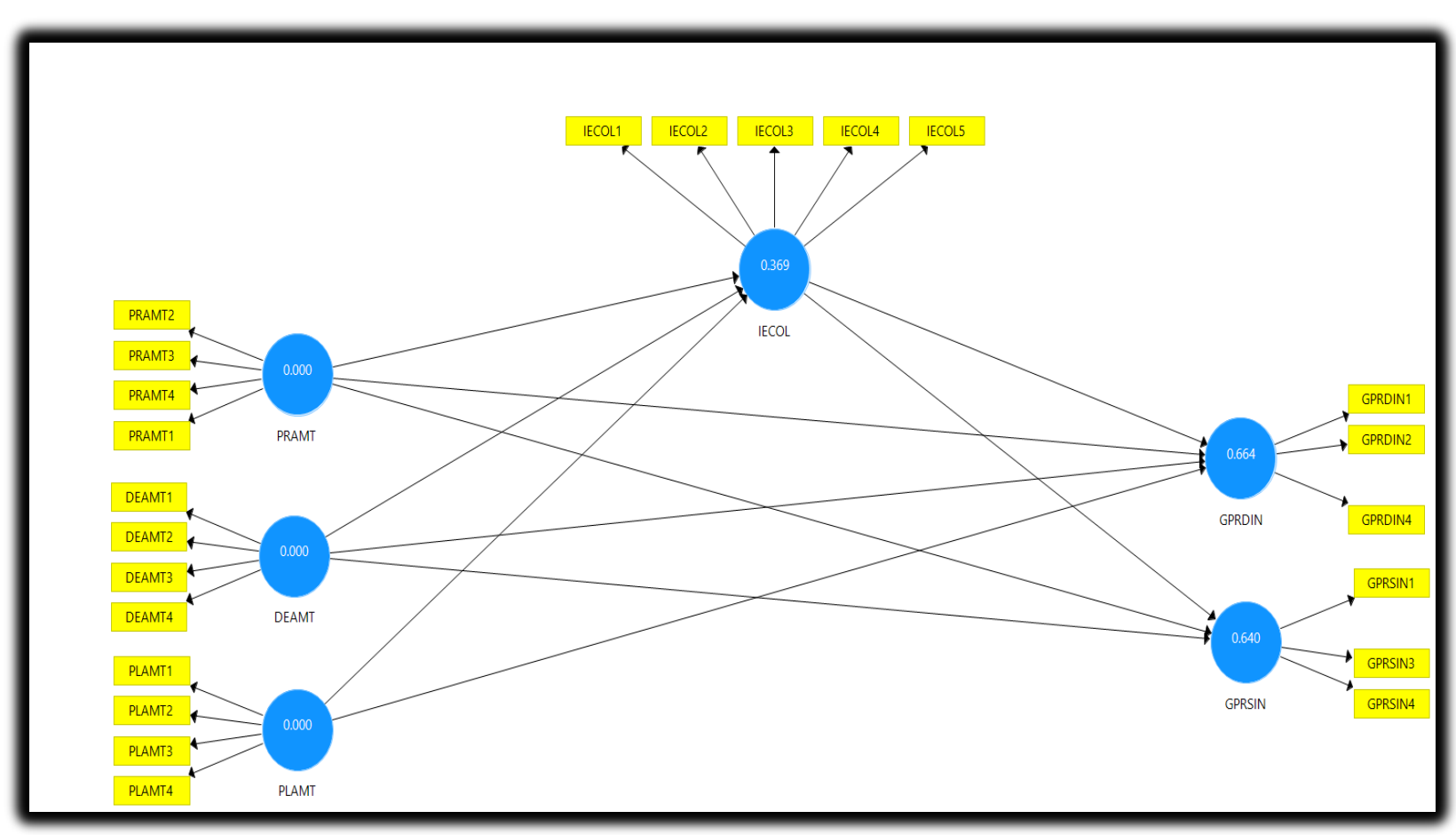

Figure 4. Q-square. 
For the assessment of comparative analytical relevance of construct of predictor of an endogenous construct we use the measure of predictive relevance. It helps to determine the relevance of the reflective construct in a structural equation modelling (SEM) model. In this study, Q2 was calculated in Smart PLS 3 using blindfolding procedure. Cross validated redundancy approach was used in this study to determine the predictive relevancy of the constructs. This is because, according to Hair et al. (2014), cross validated redundancy approach includes the elements of structural model, path model and predicted eliminated data in its assessment.

Table 7. Q-square.

\begin{tabular}{|l|l|l|l|}
\hline & SSO & SSE & $\mathbf{Q}^{2}$ (=1-SSE/SSO) \\
\hline DEAMT & 868.000 & 868.000 & \\
\hline GPRDIN & 651.000 & 218.975 & 0.664 \\
\hline GPRSIN & 651.000 & 234.393 & 0.640 \\
\hline IECOL & $1,085.000$ & 684.280 & 0.369 \\
\hline PLAMT & 868.000 & 868.000 & \\
\hline PRAMT & 868.000 & 868.000 & \\
\hline
\end{tabular}

\section{CONCLUSION}

The results show the important mediating role of internal environmental collaboration between the green innovation and MMT. For the examination of fundamental mechanism, the current study has addressed the need for empirical study that how the adoption of MMT increase the green innovation. The results have provided the beneficial extension of MMT and GI by ensuring that for the firms it is important to understand the fundamental relation between the adoption of MMT and fostering green innovation. For the adoption of MMT and fostering the green innovation the results of current study have provided the important suggestions. Firstly, the results have suggested that firms' managers who are looking for the improving the green innovation must divert their attention towards the adoption of MMT (Bajwa, 2018). The firms can obtain the important knowledge about different technological resources with the implementation of different types of MMT, which in general will improve the process innovation and green product. So, the managers of firms must employee the MMT proactively as its very beneficial investment. Whereas the managers must strike a balance and find an ideal level of adopting MMT as its use is not free. In the Meantime, the managers who are seeking or planning to use MMT must considered the dimensions of Gl carefully. Secondly the results of current study also indicate for the managers it's important to be aware with the important mediating effect of IEC as for the enhancement of green innovation the developing MMT is not enough. Through the internal environmental collaboration, the process innovation and green product both are accomplished (Dangelico, 2016). The complete understanding of crucial mediating role of IEC can make a firm to reconsider their application activities of MMT. Additionally, the results of current study are useful particularly for the managers of sports manufacturing industry of Thailand, who want to improve their Gl by adopting the different types of MMT. In Thailand the environment degradation is an important issue. For example, in GDP the increase in average annual growth is also the reason of consuming the high rate of resources and generating the pollution (Azam \& Khan, 2017). So, the managers of sports manufacturing industry of Thailand need to make the serious efforts to be green. The current study has also contributed in the existing literature of green innovation. Firstly, it contributed in the literature by adding MMT as possible ancestor and test the association between the different types of MMT and particular dimensions of GI. The aim of earlier studies was on highlighting the benefits of MMT on innovation, but they have not examined the typical importance of using MMT for green innovation. The current study has also enriched the existing literature of green innovation ad 
increase our understanding the value of adopting MMT for increasing the green innovation, by including the planning process and design MMT and with incorporation of green process innovation and green product.

\section{REFERENCES}

Aboelmaged, M. G. (2014). Predicting e-readiness at firm-level: An analysis of technological, organizational and environmental (TOE) effects on e-maintenance readiness in manufacturing firms. International Journal of Information Management, 34(5), 639-651. https://doi.org/10.1016/j.jijinfomgt.2014.05.002

Ahmadian, S., \& Abdolmaleki, S. (2018). Network typology and international opportunity recognition: moderating role of entrepreneurial orientation. Journal of Global Entrepreneurship Research, 8(1), 17. https://doi.org/10.1186/s40497-018-0104-8

Aluko, O. A. (2017). Drivers of green shipping practices adoption and impact on organisational performance. Brunel University London.

Amaro, S., \& Duarte, P. (2016). Modelling formative second order constructs in PLS. Paper presented at the European Conference on Research Methodology for Business and Management Studies.

Azam, M., \& Khan, A. Q. (2017). Growth-corruption-health triaca and environmental degradation: empirical evidence from Indonesia, Malaysia, and Thailand. Environmental Science and Pollution Research, 24(19), 16407-16417. https://doi.org/10.1007/s11356-017-9299-4

Bajwa, M. M. T. (2018). Closed-loop Supply Chain: A Systematic Review. University of Waterloo.

Bharadwaj, A. (2018). Environmental regulations and innovation in advanced automobile technologies: Perspectives from Germany, India, China and Brazil: Springer.

Bromiley, P., \& Rau, D. (2016). Operations management and the resource based view: Another view. Journal of Operations Management, 41, 95-106. https://doi.org/10.1016/j.jom.2015.11.003

Charter, M., \& Tischner, U. (2017). Sustainable solutions: developing products and services for the future: Routledge.

Cui, A. S., \& Wu, F. (2016). Utilizing customer knowledge in innovation: antecedents and impact of customer involvement on new product performance. Journal of the Academy of Marketing Science, 44(4), 516-538. https://doi.org/10.1007/s11747-015-0433-x

Dahab, S., Maag, S., \& Bagnato, A. (2016). A learning based approach for green software measurements.

Dangelico, R. M. (2016). Green product innovation: where we are and where we are going. Business Strategy and the Environment, 25(8), 560-576. https://doi.org/10.1002/bse.1886

Dangelico, R. M., Pujari, D., \& Pontrandolfo, P. (2017). Green product innovation in manufacturing firms: A sustainability-oriented dynamic capability perspective. Business Strategy and the Environment, 26(4), 490-506. https://doi.org/10.1002/bse.1932

Doppelt, B. (2017). Leading change toward sustainability: A change-management guide for business, government and civil society: Routledge. https://doi.org/10.4324/9781351278966

Enkel, E., Groemminger, A., \& Heil, S. (2018). Managing technological distance in internal and external collaborations: absorptive capacity routines and social integration for innovation. The Journal of Technology Transfer, 43(5), 1257-1290. https://doi.org/10.1007/s10961-017-9557-0

Epelbaum, F. M. B., \& Martinez, M. G. (2014). The technological evolution of food traceability systems and their impact on firm sustainable performance: A RBV approach. International Journal of Production Economics, 150, 215-224. https://doi.org/10.1016/j.ijpe.2014.01.007

Hair, Hult, G. T. M., Ringle, C., \& Sarstedt, M. (2016). A primer on partial least squares structural equation modeling (PLS-SEM): Sage publications. https://doi.org/10.3926/oss.37 
Hair, Hult, G. T. M., Ringle, C. M., \& Thiele, K. O. (2017). Mirror, mirror on the wall: a comparative evaluation of composite-based structural equation modeling methods. Journal of the Academy of Marketing Science, 45(5), 616-632. https://doi.org/10.1007/s11747-017-0517-x

Hair, Sarstedt, M., Hopkins, L., \& Kuppelwieser, V. (2014). Partial least squares structural equation modeling (PLS-SEM) An emerging tool in business research. European Business Review, 26(2), 106-121. https://doi.org/10.1108/ebr-10-2013-0128

Hamdoun, M., Jabbour, C. J. C., \& Othman, H. B. (2018). Knowledge transfer and organizational innovation: Impacts of quality and environmental management. Journal of Cleaner Production, 193, 759-770. https://doi.org/10.1016/i.jclepro.2018.05.031

Haseeb, M., Hussain, H., Kot, S., Androniceanu, A., \& Jermsittiparsert, K. (2019). Role of Social and Technological Challenges in Achieving a Sustainable Competitive Advantage and Sustainable Business Performance. Sustainability, 11(14), 3811. https://doi.org/10.3390/su11143811

Haseeb, M., Hussain, H., Slusarczyk, B., \& Jermsittiparsert, K. (2019). Industry 4.0: A Solution towards Technology Challenges of Sustainable Business Performance. Social Sciences, 8(5), 184. https://doi.org/10.3390/socsci8050154

Henseler, J., Ringle, C. M., \& Sarstedt, M. (2015). A new criterion for assessing discriminant validity in variance-based structural equation modeling. Journal of the Academy of Marketing Science, 43(1), 115-135. https://doi.org/10.1007/s11747-014-0403-8

Huenteler, J., Ossenbrink, J., \& Schmidt, T. S., Hoffmann, Volker H. (2016). How a product's design hierarchy shapes the evolution of technological knowledge-Evidence from patent-citation networks in wind power. Research Policy, 45(6), 1195-1217. https://doi.org/10.1016/i.respol.2016.03.014

Invernizzi, D. C., Locatelli, G., \& Brookes, N. J. (2018). The need to improve communication about scope changes: frustration as an indicator of operational inefficiencies. Production Planning \& Control, 29(9), 729-742. https://doi.org/10.1080/09537287.2018.1461949

Jermsittiparsert, K. \& Srisawat, S. (2019). Complexities in a Flexible Supply Chain and the Role of Knowledge Transfer. Humanities and Social Sciences Reviews, 7(2), 531-538. https://doi.org/10.18510/hssr.2019.7263

Jha, C. K. (2016). Supply chain optimization approaches and market demand analysis of petroleum industry: A case study of ONGC. International Journal of scientific research and management (IJSRM), 4(7), 4461-4475. https://doi.org/10.18535/ijsrm/v4i7.15

Kong, T., Feng, T., \& Ye, C. (2016). Advanced manufacturing technologies and green innovation: The role of internal environmental collaboration. Sustainability, 8(10), 1056. https://doi.org/10.3390/su8101056

Kyriakopoulos, G. L., \& Arabatzis, G. (2016). Electrical energy storage systems in electricity generation: Energy policies, innovative technologies, and regulatory regimes. Renewable and Sustainable Energy Reviews, 56, 1044-1067. https://doi.org/10.1016/i.rser.2015.12.046

Karle Pravin P, Dhawale Shashikant C. "Manilkara zapota (L.) Royen Fruit Peel: A Phytochemical and Pharmacological Review." Systematic Reviews in Pharmacy 10.1 (2019), 11-14. https://doi.org/10.5530/srp.2019.1.2

Lucangioli.S. "Acute Renal Failure: An Article Critique." International Journal of Pharmacy Research \& Technology 8.2 (2018), 51-52. https://doi.org/10.31838/ijprt/08.02.07

Lii, P., \& Kuo, F.-I. (2016). Innovation-oriented supply chain integration for combined competitiveness and firm performance. International Journal of Production Economics, 174, 142-155. https://doi.org/10.1016/i.jipe.2016.01.018

Lin, Y.-H., \& Chen, Y.-S. (2017). Determinants of green competitive advantage: the roles of green knowledge sharing, green dynamic capabilities, and green service innovation. Quality \& Quantity, 51(4), 1663-1685. https://doi.org/10.1007/s11135-016-0358-6 
Lin, R., Gui, Y., Xie, Z., \& Liu, L. (2019). Green governance and international business strategies of emerging economies' multinational enterprises: A multiple-case study of chinese firms in pollutionintensive industries. Sustainability, 11(4), 1013. https://doi.org/10.3390/su11041013

Lonial, S. C., \& Carter, R. E. (2015). The impact of organizational orientations on medium and small firm performance: A resource-based perspective. Journal of Small Business Management, 53(1), 94-113. https://doi.org/10.1111/jsbm.12054

Ma, Y., Hou, G., \& Xin, B. (2017). Green process innovation and innovation benefit: The mediating effect of firm image. Sustainability, 9(10), 1778. https://doi.org/10.3390/su9101778

Merino, D., Ludueña, L. N., \& Alvarez, V. A. (2018). Dissimilar tendencies of innovative green clay organo-modifier on the final properties of poly ( $\varepsilon$-caprolactone) based nanocomposites. Journal of Polymers and the Environment, 26(2), 716-727. https://doi.org/10.1007/s10924-017-0994-5

Parida, V., Sjödin, D. R., \& Lenka, S., Wincent, Joakim. (2015). Developing global service innovation capabilities: How global manufacturers address the challenges of market heterogeneity. ResearchTechnology Management, 58(5), 35-44. https://doi.org/10.5437/08956308x5805360

Raman, A. (2016). How do social media, mobility, analytics and cloud computing impact nonprofit organizations? A pluralistic study of information and communication technologies in Indian context. Information Technology for Development, 22(3), 400-421. https://doi.org/10.1080/02681102.2014.992002

Sardá, R., \& Pogutz, S. (2018). Corporate Sustainability in the 21st Century: Increasing the Resilience of Social-Ecological Systems: Routledge. https://doi.org/10.4324/9781315180908

Schubert, T., \& Tavassoli, S. (2019). Product Innovation and Educational Diversity in Top and Middle Management Teams. Academy of Management Journal(ja). https://doi.org/10.5465/amj.2017.0741

Sirkeck, S., \& Gupta, A. K. (2017). Application of Green Construction Technology in Construction Management.

Subramanian, N., Gunasekaran, A., \& Abdulrahman, M. (2019). Out-in, in-out buyer quality innovation pathways for new product outcome: Empirical evidence from the Chinese consumer goods industry. International Journal of Production Economics, 207, 183-194. https://doi.org/10.1016/j.ijpe.2016.11.009

Trianni, A., Cagno, E., \& Farné, S. (2016). Barriers, drivers and decision-making process for industrial energy efficiency: A broad study among manufacturing small and medium-sized enterprises. Applied Energy, 162, 1537-1551. https://doi.org/10.1016/j.apenergy.2015.02.078

Wuryaningrat, N., Kindengan, P., \& Sendouw, G., Lumanouw, Bode. (2018). Employee Fit, Trust, Knowledge Sharing and Innovation Capabilities: Empirical Study on Indonesia Creative Industry.

Zhang, F., \& Zhu, L. (2019). Enhancing corporate sustainable development: Stakeholder pressures, organizational learning, and green innovation. Business Strategy and the Environment, 28(6), 10121026. https://doi.org/10.1002/bse.2298

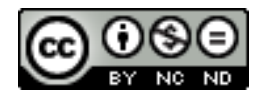

This work is licensed under a Attribution-NonCommercial-NoDerivatives 4.0 International (CC BY-NC-ND 4.0). 